\title{
Construção de identidade e trajetória social desviante: um estudo empírico com guardadores de carros em Pelotas, RS.
}

\author{
Guillermo Stefano Rosa Gómez ${ }^{1}$
}

\begin{abstract}
Resumo: Nesta pesquisa, buscou-se compreender as trajetórias profissionais de um grupo de guardadores de carros da cidade de Pelotas, analisando suas experiências de trabalho, cotidiano, e relações no mercado de trabalho. 0 foco foi entender a percepção dos atores sobre os papéis atribuídos a eles por outrem e suas reações a estes papéis (negativos), utilizando o conceito de desvio como produto da interação entre agentes e a relação que uma atribuição desviante tem com a construção de uma identidade social que parte da oposição dual entre a identidade para si e para outrem. Procuro demonstrar de que maneira a influência da moralidade da rua, age sobre os julgamentos dos sujeitos que nela trabalham e como estes sujeitos constroem sua identidade. As técnicas metodológicas, de contato direto entre pesquisador e pesquisado variaram - entrevista gravada, anotações em caderno de campo e conversa informal - de acordo com a disposição e situação do entrevistado. Ao analisar narrativas dos trabalhadores, foi possível encontrar uma queixa recorrente que a categoria é malvista socialmente e ao guardador é atribuído o rótulo de "ladrão" ou "drogado". Dessa forma, o trabalhador busca minimizar a rotulação através de uma série de ações estratégicas que incluem uma rotina de trabalho rígida e um "código de conduta" regido pela sobriedade. Na relação com colegas que desviam destas regras, os trabalhadores acabam produzindo uma etiquetagem "interna", para classificar e identificar desviantes que destoam do guardador "batalhador" e que "corre atrás". Nas conclusões, sintetizo as descobertas do estudo, suas limitações empíricas e possibilidades de expansão.
\end{abstract}

Palavras-chave: desvio, identidade social, moralidade da rua, informalidade, guardadores de carro.

\section{Introdução}

Ao selecionar a cidade industrial e a urbanização como problemática sociológica da modernidade, Henri Lefebvre destaca o automóvel como um elemento fundamental e parte constituinte da planificação urbanística que se orienta seguindo as lógicas do capital, da rua transformada em vitrine de circulação de mercadoria. 0 automóvel implica em uma série de questões a esse respeito e faz com que seu estacionamento se torne "uma obsessão"; sua circulação, "um objetivo prioritário" (LEFEBVRE, 1999 p.29).

Neste trabalho busco compreender a construção de identidade de uma profissão que surge justamente como uma adaptação ou consequência para a superlotação de carros e de seu estacionamento: os chamados "guardadores" ou "cuidadores" de carros na cidade de Pelotas. 0 artigo é resultado de pesquisa empírica realizada em 2014 que teve como objetivo comparar e analisar experiências de trabalho, cotidiano, itinerários pessoais e profissionais destes sujeitos. 0 intuito foi conhecer, registrar e analisar, apoiado na perspectiva teórica da Sociologia do Desvio, o estar na rua - espaço dos mendigos, dos pedintes, dos sem-teto - na qual, camelôs, prostitu-

1 Graduando em Ciências Sociais - Bacharelado, pela Universidade Federal de Pelotas (UFPel). 
-tas, ambulantes e guardadores compartilham o "não-reconhecimento" do ponto de vista sócio cultural.

Através de entrevistas com os trabalhadores em seu ambiente de trabalho, ouvi e registrei seus relatos. Diante de negativas de alguns dos sujeitos abordados e seus argumentos para não participar da entrevista, agreguei dados que considerei importantes. Essas entrevistas, produzidas pelo contato direto entre pesquisador e pesquisado, efetivadas tanto através de conversas informais, como diálogos gravados, circunscrevem um cenário de interações e relações humanas no mundo do trabalho e, também, no espaço urbano. As técnicas metodológicas foram sendo adaptadas e alternadas, conforme a disponibilidade e a situação em que se encontravam cada um dos entrevistados.

Quando parti para a análise dessas narrativas, percebi ser recorrente a percepção, por parte dos guardadores de carros, de que a sua identidade sofre o efeito de classificações e rótulos negativos como "drogado", "louco", "ladrão" e que provoca "medo", entre outras. Esses rótulos são combatidos pelo trabalhador que "corre atrás", que projeta para si, uma identidade diferente. Perceptível, também, a relação de amizade com transeuntes frequentes das ruas ou quadras pelas quais o guardador é responsável; de conquista de clientela e dos equipamentos urbanos que fazem parte do cotidiano profissional do entrevistado como lojas, estacionamentos particulares e restaurantes da sua rua.

As narrativas são trazidas para o texto através de citações literais, entre aspas, e menções aos diálogos, tirados de anotações do diário de campo - ferramenta metodológica importantíssima para a pesquisa -. Algumas vezes, no corpo do texto, foram utilizadas letras maiúsculas, em negrito, para diferenciar um entrevistado de outro.

Obtive também, negativas. Em um dos casos, o contatado se recusou a falar dizendo que "não poderia falar sobre isso" (o trabalho de guardador de carros) e indicou "o guardador daquela quadra ali, nosso representante". Mesmo explicando que não almejava informações gerais sobre guardadores, apenas a perspectiva do contatado sobre seu trabalho, sua própria rotina de trabalho e sua trajetória particular no mercado de trabalho, se já teve outros empregos e quais empregos eram esses, ele reiterou que eu falasse com "o representante", na outra quadra.

Em outro caso, quando abordei o guardador, que era um rapaz jovem, este se mostrou pouco confortável desde o início, por isso não mencionei nenhum registro de qualquer caráter (escrito ou gravado). Apesar disso, não quis informar nome, idade ou horário de trabalho. Contou que estava no lugar do pai - que tinha aquele ponto há oito anos - e, sobre o trabalho, afirmou "não tenho como não gostar". 
A profissão de guardador de carro é permeada pela "rotulação" por outrem, e esse fato é expressivamente percebido - e relatado - pelos guardadores, que reagem de diferentes maneiras a este rótulo e também atribuem "etiquetas" a seus colegas de profissão, por razões similares às que são vistos como desviantes pelas pessoas em geral. Ao entender que é visto como "marginal”, reage ao rótulo, pois essa generalização da categoria, prejudica o trabalho do guardador. Um dos entrevistados relatou que as pessoas "pensam que todo guardador rouba". 0 desvio, combatido ou incorporado é um fator de enraizada influência na construção das identidades profissionais destes trabalhadores. Por essa razão, o problema de pesquisa se relaciona com a teoria interacionista do desvio, e as teorias interacionistas em geral, porque "prestam atenção à forma como os atores sociais se definem uns aos outros (..)" (BECKER, 2008, p 204). 0 foco deste estudo está em analisar o desvio do ponto de vista do próprio ator - o guardador -, e de como ele percebe que é percebido, portanto, da sua reflexão sobre a própria atividade profissional.

Além do desvio, outra categoria teórica fundamental, que auxilia a estruturar a problematização da pesquisa, é a de identidade social da qual o processo de elaboração é sempre uma relação negociada entre a identidade para si e para outrem, de acordo com Claude Dubar (1997). 0 processo identitário biográfico (identidade para si) está fundamentado em como o indivíduo quer ser visto pelos outros, qual a trajetória que ele visa passar para o coletivo. Já o processo identitário relacional (para outrem), o outro elemento dessa dualidade, fundamenta-se na percepção que os outros têm do indivíduo, da sua posição na realidade social. Trata-se de identidades "atribuídas" ou "propostas", que podem ser aceitas ou não. É bastante claro como esse processo de "negociação" (DUBAR, 1997, p.108) está relacionado com o desvio, afinal, as definições de rótulos ou etiquetas também são negociadas mediante interações entre atores em seus processos de atribuições ou afirmações identitárias no mundo social.

Uma variável especialmente importante para o estudo da trajetória desviante de um grupo profissional como os guardadores de carro é levar em conta o impacto da rua para uma identificação, ou rotulação social. Roberto DaMatta (1997) em sua clássica distinção entre casa e a rua propõe uma diferenciação de frequentadores, nível de moral, em cada categoria. Mais especificamente, a rua como o lugar de "personagens perigosos", dos "limites do desconhecimento" e é esta ferramenta teórica que usarei para relacionar com as narrativas dos guardadores de carros, uma profissão urbana, industrial e "da rua". Dessa maneira, é de extrema importância pensar de que forma a moralidade atribuída a um espaço - como a rua -, traz consequências para o lado micro, isto é, está presente na construção de identidade dos 
indivíduos que trabalham nela.

0 desenvolvimento do trabalho começa por um esclarecimento do conceito de desvio, fundamentalmente de Becker (2008), com contribuições importantes da antropologia de Gilberto Velho (2013) e de alguns diálogos com a pesquisa realizada com prostitutas por Maria Dulce Gaspar (1985). Logo depois, uma menção ao conceito de informalidade, o desenvolvimento do mercado de trabalho no Brasil e um estudo da condição dos trabalhadores entrevistados no mercado de trabalho, comparando sua atual ocupação com experiências profissionais anteriores, realizando algumas hipóteses. $\mathrm{Na}$ análise mais profunda do caso empírico estudado, através dos trechos das narrativas e amparo teórico, analisei qual o caráter do desvio como é percebido - e, em seguida, qual a sua implicação na vida dos trabalhadores e como estes reagem a ele no seu cotidiano profissional. Busco apresentar quais as estratégias usadas para combater o rótulo desviante, pois, este não é desejado, visto o caráter de serviço desta ocupação, ou seja, tem como princípio fundamental a interação entre trabalhador (prestador de serviço) e seus clientes. Por fim, pretendo demonstrar como essas reações acabam produzindo um deslocamento do papel de desviante para o que atribui o desvio a outros, gerando outro grupo desviante dentro da mesma categoria profissional, apresentando o guardador informal-moral (não drogado, não ladrão, honesto, batalhador), versus o guardador informal-imoral (drogado, o que se aproveita do ponto, que faz com que a profissão seja "malvista"). Não pretendo com esses dois termos, subscrever a complexidade da realidade social a categorias que a simplificariam, busco apenas uma explicação sistemática deste recorte, desta amostragem.

Para compreender as reações ao desvio percebido, utilizo, além do referencial teórico já citado, a noção de experiência social de François Dubet (1994). A experiência social é, por um lado, uma "maneira de sentir" e, também, uma maneira particular de "construir o real", de o "verificar" (p. 95), uma maneira de vivenciar a realidade social. Discutindo em termos teóricos, a experiência social é uma forma de combinar diferentes lógicas que provem, por sua vez, de diferentes esferas do sistema social "e é a dinâmica gerada por esta atividade [de combinação] que constitui a subjectividade do actor e sua reflectividade" (DUBET, 1994, p.107). As lógicas de ação são três: A integração, que delimita os valores apreendidos, as normas sociais, decorrentes do processo de socialização do ator. Para compreender as reações ao desvio percebido, utilizo, além do referencial teórico já citado, a noção de experiência social de François Dubet (1994). A experiência social é, por um lado, uma "maneira de sentir" e, também, uma maneira particular de "construir o real", de o "verificar" (p. 95), uma maneira de vivenciar a realidade social. Discutindo em termos 
teóricos, a experiência social é uma forma de combinar diferentes lógicas que provem, por sua vez, de diferentes esferas do sistema social "e é a dinâmica gerada por esta atividade [de combinação] que constitui a subjectividade do actor e sua reflectividade" (DUBET, 1994, p.107). As lógicas de ação são três: A integração, que delimita os valores apreendidos, as normas sociais, decorrentes do processo de socialização do ator. Esta lógica produz a identidade integradora, onde o indivíduo apresenta-se conforme a herança que recebeu dos valores que o socializaram. A competição, a lógica do mercado, exige do ator um comportamento estratégico, competitivo, que estabelece uma identidade recurso. A identidade recurso é a construção de si mediante as regras do jogo, da competição dos "adversários e aliados", da diferenciação em um campo de disputas. A lógica de subjetivação - mais importante para este estudo -, a lógica do sujeito, está associada a uma reflexão crítica e interna sobre seu papel. Significa uma superação do processo de alienação que reduz os atores a "serem apenas os suportes dos papéis e os agentes de interesses limitados impostos, uns e outros, pelos dominantes ou pelo 'sistema'” (p. 134). A subjetivação vai contra esse processo de imposição. Nela, o ator retoma suas próprias ações de maneira crítica e flexiona-se como um sujeito. As ações de percepção e de reação ao rótulo e, do conflito subjetivo entre identidade para outrem e para si, estão imbricadas a este processo de reflexão.

\section{O Desvio - Categoria de interação}

A noção de desvio está associada à "infração de alguma regra geralmente aceita" (BECKER, 2008, p, 21). No entanto, o comportamento de um indivíduo desviante está diretamente associado à percepção que os outros têm de suas ações, que podem ser caracterizadas como um deslize perante as normas. Dessa forma, "desvio não é uma qualidade que reside no próprio comportamento, mas na interação entre a pessoa que comete um ato e aqueles que reagem a ele" (BECKER, 2008, p. 27). Portanto, o desvio não é uma patologia, onde indivíduos com características anômicas, para usar o conceito de Durkheim, definido "pela desintegração social e pela debilidade dos laços que prendem o indivíduo ao grupo" (ARON, 2008, p. 486) que para o autor clássico, seria um resultado da sociedade moderna. Na concepção interacionista, ele deve ser percebido como produto de um conjunto de relações sociais que envolvem relações de poder. Interações entre grupos que fazem regras e produzem "sugestões de comportamento" (VELHO, 2013), que geram caracterizações desviantes para aqueles que não as seguem. Até mesmo o conceito de profissão está ligado a um reconhecimento, uma autorização social de determinado trabalho ou comportamento, como demonstrado por Everett Hugues (1958): "Many (...) occupations have sought 
for themselves the envied status of profession" 2, algumas delas, "succeed in gaining that esteem, that broad license to control their work and that social mandate over affairs pertaining to it that the term profession connotes" ${ }^{3}$.

O domínio de determinada técnica ou recurso, não é suficiente para consolidar um grupo profissional. Ela necessita de uma aceitação do meio social em que está inserida. Obviamente, certos grupos são mais prestigiados que outros e alguns, como os guardadores de carros ou as prostitutas (GASPAR, 1985), são vistos como "perigosos" e/ou "marginais", tendo como princípio que um "comportamento desviante é aquele que as pessoas rotulam como tal” (BECKER, 2008 p. 22).

Em acordo com as informações apresentadas, na perspectiva de Gilberto Velho (2013), o desvio não deve ser encarado do ponto de vista funcionalista, de comportamento anômico e, sim, como produto de uma "leitura divergente" (p.50) que o sujeito faz da realidade. Enfatizando o "caráter multifacetado, dinâmico e muitas vezes ambíguo da vida sociocultural" (VELHO, 2013 p. 45) onde diferentes atores, sejam eles indivíduos ou grupos, tem para si diferentes conjuntos de regras e formas de experimentar a realidade social. Na relação entre estes atores não há ausência de poder, pelo contrário, o domínio político de um determinado grupo forçará uma predominância de "valores dominantes", dos quais os que não fazem parte se tornam desviantes. Ainda para Velho, a noção de desvio é bastante situacional. 0 indivíduo ou grupo desviante deve ser reconhecido como tal por outrem em alguma atividade, mas existem casos nos quais os papéis podem mudar. "Ele não será sempre desviante. Existem áreas de comportamento em que agirá como qualquer cidadão normal" (VELHO, p.50), conforme o contexto e a situação.

Ao definir o desvio Becker (2008) situa, de um lado, os criadores de regras ou empreendedores morais. São os que têm o poder necessário para estabelecer normas e cobrar sua aplicação. Em oposição, há os "destoantes" desse conjunto de normas, que seguem uma trajetória que não se encaixa nesse consenso, os outsiders. Os desviantes são aqueles indivíduos que assumem, ou não, comportamentos não prescritos ou censurados pela norma. Partindo para termos empíricos, segundo os relatos colhidos entre os trabalhadores, a profissão dos guardadores de carro é vítima de "preconceito" no próprio termo dos entrevistados, que também se referem ao "medo" que alguns têm deles. Como tento sugerir neste texto, o fato de serem membros de uma ocupação "da rua", influencia neste processo, no qual o trabalhador recebe os rótulos de "drogado" ou "ladrão".

2 Muitas(...) ocupações tem procurado para si o invejado status de profissão" (tradução livre).

3 Foram bem sucedidas ao ganhar essa estima que concede a licença para o controle do seu trabalho e da autoridade social sobre atribuições pertencentes a ele que o termo profissão conota" (tradução livre). 


\section{A informalidade}

A formação histórica do mercado de trabalho no Brasil foi marcada pela presença forte do Estado e da concepção de mercado formal, como padrão. A regulamentação deste mercado, realizada através de acentuada intervenção estatal. 0 conceito de cidadania regulada (SANTOS, 1979) serve adequadamente para compreender esta realidade. Nela, existe uma relação direta entre o emprego e os direitos sociais de um cidadão. Esta relação, coordenada pelo Estado através de leis ${ }^{4}$, dita que somente as profissões reconhecidas por ele, as do "mercado formal", têm direitos sociais assegurados. Desde a constituição de um mercado em maior escala (pós Abolição da Escravatura) até as primeiras medidas legais para regulamentação do trabalho, no governo Getúlio Vargas da década de 30, o Estado brasileiro influenciou fortemente as normas de como operar no mercado de trabalho (THEODORO, 2004). 0 modelo de cidadania regulada influencia o mercado de trabalho no país até hoje. As ocupações que se situam fora desse reconhecimento ${ }^{5}$ institucional são tradicionalmente chamadas de "informais". Embora alguns trabalhos destaquem a "polissemia" deste conceito ${ }^{6}$ utilizo o conceito em termos gerais para demonstrar a condição dos guardadores de carro no mercado de trabalho. Uma definição relevante de informalidade é a de Mário Theodoro:

\footnotetext{
“... uma parte da força de trabalho que engloba os trabalhadores não inseridos nas relações assalariadas, ou seja, aqueles que se dedicam ao trabalho autônomo e a atividades de pequena escala organizados em microunidades de produção de bens ou de serviços, assim como os assalariados não declarados e aqueles trabalhadores sem remuneração" (THEODOR, 2004, p. 78)
}

A profissão do guardador de carros, identificada como informal, também pode ser entendida dentro da dimensão atual de trabalho enquanto relação de serviços (DUBAR, 2009). Dessa maneira, a dimensão da informalidade, oriunda da análise do mercado de trabalho, é importante para pensar questões como o processo de aproximar-se do cliente e conquistar sua confiança mesmo na informalidade. Também deve-se levar em conta a influência de estar no mercado de trabalho informal para a construção de uma identidade social e profissional do trabalhador e entender o combate deste ao rótulo negativo.

Ainda sobre a questão informal, destaco parte da entrevista realizada junto à Secretaria de Gestão da Cidade e Mobilidade Urbana da Administração Municipal:

4 Como impositor de regras, se pensarmos na sociologia proposta por Becker.

5 Aqui é possível o diálogo com o conceito de profissão de Hugues(1958), exposto anteriormente.

6 (Noronha, 2003), é um dos exemplos, onde a noção aparece "confundida" com os temos "ilegal ou "injusto". 


\begin{abstract}
"Porque o guardador o que ele é? Ele não existe, não tem um seguro social, não tem uma garantia de emprego nenhum, não tem nada. Ele é uma pessoa que se diz dona daquele pedaço de quadra". "Como é que ele se intitulou dono, como é que ele chegou até ali, a gente não sabe e não se sabe nada da idoneidade daquela pessoa pra fazer esse tipo de trabalho".
\end{abstract}

A ocupação de guardador é marcada pela instabilidade, ausência de previdência ou algum seguro-desemprego. Porém, contrariando a possível atribuição negativa desta condição, nas entrevistas os guardadores de carros mostram adaptação, atribuição de valor a sua profissão, maior independência - "aqui, não tenho patrão pra me mandar" - e menos insalubridade, em comparação a outras experiências profissionais, como as de pedreiro, porteiro, borracheiro, carregador de fretes ${ }^{7}$. Um dos entrevistados comparou ser guardador com o antigo trabalho na construção civil, dizendo: "Era muito chato [o trabalho de pedreiro], aqui entro em contato com várias pessoas. 0 doutor, o advogado, o funcionário público, o estudante". A comparação com o trabalho repetitivo e pouco recompensador, em um frigorífico, fez outro entrevistado preferir sua ocupação atual: "Fazia três feição lá: guampa, beiço e olho, em doze segundos, mas não rendia como rende aqui, tinha que fazer um monte de hora extra pra fazer salário". Ele ainda se orgulha de ter comprado o próprio carro com a profissão de guardador: "Eu venho no volante! (risos). Eu corro atrás, né, cara. O cara vai juntando uma moedinha hoje, deixa guardado, lá... no final do ano, tu faz uma boladinha (...)".

De um modo geral, os trabalhadores entrevistados apresentam informações biográficas que levam a uma hipótese de pesquisa na qual essas características os colocariam em situação de fragilidade no mercado formal, como a baixa escolaridade ${ }^{8}$ ou ausência de cursos profissionalizantes e, dessa forma, recorrendo à informalidade, indo parar nela ao acaso, ou por escolha, desenvolvem uma série de estratégias, de diferenciação profissional, que servem tanto para o sucesso com os clientes, como para a superação da condição de desvio percebida, como veremos adiante.

Todos precisaram "se virar" desde cedo, contribuir para a renda da casa. " $\mathrm{A}$ " vem de um lar de baixa renda e tinha muitos irmãos; “B”, começou a trabalhar aos sete anos, cuidado animais no campo, para contribuir com a renda da casa; "C" não teve o pai presente no lar, filho de mãe solteira, empregada doméstica; “D” perdeu o pai, num acidente doméstico. Esse cenário - ilustrado pela fragilidade perante o mercado formal por nenhum dos entrevistados ter conseguido concluir o Ensino Fundamental - dificultou o desenvolvimento de qualificações, que significaria "dispor de uma

7 Todos os entrevistados tiveram múltiplas experiências profissionais anteriores, formais e informais, dentre elas as citadas e outras como: trabalho e frigorífico, curtume, vendedor de algodão doce, servidor de limpeza, etc.

8 Nenhum dos entrevistados tem o ensino fundamental completo. 
força de trabalho e garantindo uma demanda estável por sua capacidade de realizar trabalho (OFFE, 1989, p. 62). Por não poderem se diferenciar enquanto ofertantes de força de trabalho, estes trabalhadores acabam sujeitos a forte pressão substitutiva de concorrentes em condições semelhantes, precisando aceitar empregos instáveis, salários baixos e condições restritivas de trabalho. Na realidade dos guardadores de carros, a situação de trabalho é de informalidade, assim como são informais os tipos de "qualificação". A forma de falar e de tratar o cliente - ou de praticar esporte, de não usar drogas, de pagar suas contas, de ter seu carro... - possibilita um diferencial, um afastamento do sentimento de inutilidade (SENNET, 2008) que poderia ser adquirido no mercado formal. A construção de identidade como guardador, ou "segurança de automóvel" como sugerido por um entrevistado, é importante para os trabalhadores, mas ainda mais relevante é a maneira de ser o guardador, a forma como realiza o seu trabalho, sempre imbricada numa relação direta do sujeito com o outro, dimensão profundamente relacional.

\section{A Moralidade da Rua}

Uma convergência nos relatos dos entrevistados é a identificação de uma atribuição desviante de si por outrem, isto é, os guardadores percebem que são mal-vistos socialmente. Proponho que a influência simbólica da rua, como categoria sociológica, tem reflexo direto na construção de identidade de trabalhadores que se encontram nela, e, também, que uma profissão "da rua" adquire um status diferente no processo interacionista de rotulação. Neste caso, cabe a análise da realidade brasileira realizada por Roberto DaMatta (1997) e sua distinção/oposição entre casa e a rua e como essas categorias se constroem no cotidiano ideológico brasileiro. A casa, como domínio do privado, daquilo que é conhecido, controlado. A rua, como categoria, é "um domínio semidesconhecido e semicontrolado, povoado de personagens perigosos. Assim, é na rua e no mato que vivem os malandros os marginais e os espíritos, essas entidades com quem nunca se tem relações contratuais precisas. " (DAMATTA, 1997 p. 95), a ausência de conhecimento gera desconforto e medo, o que influi diretamente nas concepções de alguém "pertencente" a esse universo.

DaMatta (1997) destaca que as expressões "moleque de rua" ou "já pra rua", são poderosas e ofensivas, designando, num caso, alguém sem orientação moral ${ }^{9}$ e, no outro, um modo contundente de eliminar alguém de um ambiente preciso. Desse modo, "colocar alguém para fora de casa é sinônimo de destruição de uma posição social" (DAMATTA, 1997, p. 96). Dessa maneira, a rua, na sociedade brasileira, se configura como um lugar de limites perigosos, e que não está regido por princípios

9 Grifo nosso 
morais conhecidos.

A condição de estar na rua desencadeia uma série de pré-julgamentos, fato que tem consequências importantes para a "identidade pública" (BECKER, 2008) do sujeito que a ela está condicionado, mediante relações de trabalho. Depois de um primeiro estranhamento, de questões relativas a condição da rua, surgem outras características chamadas de status auxiliares por Howard S. Becker (2008. p.43): “A posse de um traço desviante pode ter um valor simbólico generalizado, de modo que as pessoas dão por certo que seu portador possui outros traços indesejáveis presumivelmente associados a ele". A rua funciona como um traço desviante principal, de forte valor simbólico que, inevitavelmente, influencia na classificação do sujeito por outrem, ou, pelo menos, na percepção dessa classificação pelo sujeito desviante. Isso é bastante claro ao realizar uma análise a partir das narrativas profissionais colhidas, nas quais os guardadores de carro expressam que as pessoas com as quais convivem tem "medo", "(...) tem gente que sai correndo daqui, quer me evitar mesmo" ou "acham que o guardador é ladrão" ou que é usuário de drogas. Por outro lado, a atribuição de um rótulo muitas vezes inadequado e "preconceituoso" não significa que não exista o real contato desta profissão com limites "perigosos", como narrado pelos guardadores de carro quando perguntados sobre seus colegas "Cara, eu acho que a maioria dá problema mesmo (...) só alguns é que vem pra fazer o trabalho direito", ou ainda "tem muita gente que se droga, daí acham que a gente é drogado". Essa dimensão instável, afeta a própria segurança dos trabalhadores, que correm riscos e lidam com situações perigosas, típicas de um ambiente "semidesconhecido e semicontrolado" (DAMATTA, 1997 P. 95).

A proximidade com outras dimensões mais desviantes é bastante clara. 0 mundo do crime é citado por "A": "Já fui ameaçado com faca, aí como luto artes marciais ${ }^{10}$ consegui me virar". Segundo "B": “Já vi assalto, já teve tiroteio baleando um guri aqui, o cara tinha deixado o Chevette dele aqui, é complicado pra trabalhar na rua (...), tem que saber muito bem quem tu vai atender ${ }^{11}$ e saber cuidar o movimento, né”. As drogas, outro rótulo comum aos guardadores, não são aspectos alheios ao cotidiano destes sujeitos, como descrito por "C": "Esse aí, mente que tem família, pra se drogar"; "Esse da outra quadra, chega louco, todo dia". A questão da rua afeta a situação de vida prática, através da ausência de vínculo, "se não venho, não ganho nada, não posso ficar doente", de não ter seguro de trabalho, de correr riscos: "outro dia eu vi que lá embaixo tavam roubando uma moça, mas eu fiquei com medo (...) não sei se eles tavam armados (...) e se tivessem? E esse pessoal tá sempre por aqui ${ }^{12,}$

100 esporte descrito como importante elemento nessa trajetória, servindo como diferencial que torna o trabalhador único, em seu ponto de vista "Vejo poucos fazendo"

11 Grifo nosso

12 Guardador afirmou conhecer todos os "bandidos" da sua área, "polícia vem direto aqui”. 
eles sabem onde me achar (...) se eu faço algo depois pode ter volta (...)" e ainda, da percepção moral, que afeta diretamente a condição profissional dependente de relações de confiança (DUBAR, 2009), situação descrita por um guardador, "as classes altas e médias tem medo". Apesar do medo, da atribuição de rótulos, é necessário receber algo dos clientes, que estacionam na sua rua. Dessa maneira, o trabalhador elabora algumas posturas para desmistificar o estigma. Tornar-se conhecido, dos que frequentam o seu ponto é fundamental. Dessa forma, a influência da rua como "lugar perigoso" diminui, na tentativa de criar laços de familiaridade ou "amizade", que exigem, uma postura regular - sempre estar no mesmo local - sóbria e personalizada, pois, antes de vender o serviço de "guardar um carro", o guardador vende confiança, postura moral e honestidade.

\section{Reações ao rótulo negativo: estratégias de afirmação do sujeito}

Um comportamento comum de pessoas ou grupos que agem de maneira desviante, de acordo com a teoria de Becker, é o de, ao perceberem que são considerados outsiders pela sociedade [o indivíduo desviante] "faz do desvio uma maneira de viver, organiza sua identidade em torno de um padrão de comportamento desviante" (BECKER, 2009, p.40), a partir de motivações próprias ou coletivas, para justificar sua condição desviante ${ }^{13}$.

Os guardadores de carro, em vez de tentarem justificar sua carreira desviante com argumentos subjetivos (autojustificação), tentam minimizar sua conduta desviante para transformá-la em um comportamento, socialmente aceitável e profissionalmente reconhecível, isto é, não deixar o fato de estar na rua e na informalidade se tornar um empecilho para o sucesso de seu trabalho. A reflexão sobre o desvio percebido está também associada à construção de identidade do sujeito, pois, "o discurso sobre si mesmo implica alta dose de diálogo e justificação em relação aos atributos e valores imputados" (GASPAR, 1985, p.84). 0 rótulo de desviante está relacionado a um processo de percepção do outro, do julgamento que esse outro faz do eu e de como esse eu quer ser visto pelo outro. "Cada um é identificado por outro, mas pode recusar esta identificação e definir-se de outra forma" (DUBAR, 1997 p.106). Neste sentido, o mais recorrente nas entrevistas foram relatos de processos de "atribuição" aos guardadores, percebidos pelos mesmos, quase sempre se referindo a rótulos negativos. Existe, portanto uma recusa, no momento da "incorporação", isto é, a interiorização de uma identidade pelos próprios indivíduos difere do processo de "etiquetagem" feito pelos outros (DUBAR, 1997). De acordo com Claude Dubar, o processo de atribuição está relacionado a um tipo de identidade para outrem, que são

13 É o caso dos grupos de usuários de maconha, ou de grupos mais politicamente organizados como o dos homossexuais (BECKER, 2008). 
que são características identitárias "propostas ou impostas" pelo outro. Já o processo de incorporação se situa no campo de uma identidade para si, que pode ser construída em consenso com o processo de atribuição ou em conflito com ele. 0 indivíduo pode aceitar a imagem de si que é proposta, aceitar somente parte dela, ou até mesmo recusá-la por completo e apresentar a sua própria "versão". Este processo de negociação identitária (DUBAR, 1997), no caso dos guardadores, ocorre cotidianamente, no processo de interação com uma pluralidade de atores que compõe o espaço da sua rua/quadra. Estes trabalhadores organizam uma resposta identitária, de valorização da sua função como profissão e de sua trajetória de vida como "honesta" e "batalhadora", visando uma recusa das imposições de identidade desviante.

Afinal, por caracterizar-se como prestação de serviço, o trabalho do guardador de carro envolve um contato entre o desviante e a sociedade em geral (seus clientes) e, para isso, o trabalhador faz uso de uma série de posturas estratégicas. Estas, agem, para garantir a relação do prestador de serviço com o cliente ser bem-sucedida pois, como apontado por Dubar, a relação de serviço "faz da confiança um componente central da relação, e da satisfação do cliente um elemento essencial do êxito da empresa e do reconhecimento de si" (2009, p.137). A interação entre guardadores e o público que estaciona na sua rua tem de ser "amigável", para o guardador obter seu ganho. Estas posturas de reação à identidade desviante imposta, e os vínculos de reconhecimento mútuo, entre trabalhador-cliente, que elas produzem, auxiliam na desconstrução do estigma associado a profissão.

O esforço é no sentido de conquistar seu "cliente", com o uso de, por exemplo, uma linguagem sem gírias, como relatado por um entrevistado: "Esperam ${ }^{14}$ que o guardador fale gírias, por isso procuro sempre tratar com respeito, sem essa de e aí professor, bem cuidado! ". Também de mostrar-se "diferente" dos outros guardadores, de estar no trabalho sóbrio e disposto "não pode estar com a cara fechada". 0 comportamento de reação parte de um processo crítico de um sujeito sobre seu papel social que leva em conta os papéis que lhe são impostos, mobilizando práticas cotidianas para modifica-los. A reflexão crítica sobre sua rotulação por outrem mobiliza a criação de uma postura "de cara limpa", para garantir o sucesso no mercado, com os clientes. Quando esse processo de superação do rótulo é bem sucedido, é mostrado com orgulho, na conquista de "amizade" ${ }^{15}$. As expressões práticas desse termo são múltiplas: um restaurante próximo para almoçar, conhecer outras pessoas que não estacionam, mas que passam por ali e o conhecem pelo nome, usar a "geladeira do estacionamento" próximo, receber ajuda das pessoas da região quando acontece

14 Percepção do rótulo, de uma imagem de um guardador "marginal" que fala gírias, que tem ligações com o crime, etc.

15 Termo muito empregado pelos trabalhadores nas entrevistas. 
algum problema grave ${ }^{16}$. A postura de sujeito crítico reflete diretamente na sua atuação, em seu comportamento nas interações do cotidiano, para virar a negociação identitária $^{17}$, a seu favor e superar entre o descompasso do desvio visto pelo outro e a trajetória "batalhadora" projetada por si. 0 trabalhador tenta demonstrar que "corre atrás", que sim, está na rua, mas, não é um criminoso e isso vira motivo de orgulho para afirmação pessoal e na construção de uma identidade profissional. Significa afirmar a profissão de guardador na informalidade, apesar da cidadania regulada, tentando construir a partir de suas interações cotidianas de familiaridade e sociabilidade o reconhecimento coletivo que o conceito de profissão requer. 0 sujeito tem a necessidade de projetar sua identidade e sua trajetória como "de sucesso", afinal: "O pessoal tem muita confiança em mim, não tenho do que me queixar" ou "eu até mexo com o pessoal que vou tentar vir pra vereador".

Ainda assim, são estratégias que precisam de constante alimentação, pois, ao menor deslize ou uma situação de tensão - algum roubo de carro que não necessariamente ocorre na quadra da qual o guardador é responsável - a etiqueta desviante recai novamente sobre ele. Como na situação do "doutor" que ameaçou com um revólver o guardador que vinha pedir as moedas ou, em outro caso, quando cobraram do guardador sobre um assalto que tinha ocorrido em uma quadra próxima a dele. A possibilidade de "alguém se aproveitar" de um ponto e acabar aumentando o estigma da profissão: "Se eu não apareço, pode ser que um se aproveite (...) aí alguém acha que é guardador, que tá ali olhando e quando vai entrar [no carro] o cara se aproveita (...) aí, já pensam que o guardador é assim". Afinal uma pessoa "será identificada primeiro como desviante, antes que outras identificações sejam feitas" (BECKER, 2008 p. 44).

A partir desta condição de constante incerteza perante sua identidade social, o trabalhador tem de reagir de forma adequada e isso não se dá somente no sentido de implementar sua própria prestação de serviço ou de conquistar confiança. Com esse processo de reação ao rótulo, surge, como forma de diferenciação, um segundo rótulo, que acontece na interação de trabalhador com trabalhador. 0 guardador de carros que "ganha seu pão" honestamente, aquele que "corre atrás" não quer que os outros -"colegas de profissão" - prejudiquem a confiança que obteve. Isso reflete no julgamento que este sujeito tem dos outros guardadores, percebido em afirmações como: "a maioria dá problema mesmo"; ou que se referem aos poucos que se interessaram pela luta sindical: "nas reuniões, nunca ia ninguém”; àquele da quadra ao lado que chega "completamente louco ${ }^{18 ", ~ a o ~ q u e ~ " v e m ~ p r a ~ c o n s e g u i r ~ d i n h e i r o ~ e ~ s e ~ d r o g a r ~}$

16 Dois dos entrevistados perderam a casa em incêndio.

17 Termo de Claude Dubar (1997).

180 termo "louco", e principalmente a forma como é aplicado, se assemelha bastante a palavras que são usadas para rotular os guardadores, como "drogado" e "ladrão" 
mais", ou ao que mente para seus clientes e, portanto, é um trabalhador imoral.

Em perspectivas macrossociológicas, é possível sempre problematizar a relação de trabalho com o conceito "estrutural" de classe, e confrontando com essa situação empírica, associar uma desagregação dos interesses, das motivações para com o trabalho, dentro de uma mesma classe. Essa divisão entre trabalhadores traz à tona uma discussão, particularmente interessante, de que aquele guardador estabelecido, o "batalhador", não drogado e honesto, ao mesmo tempo em que combate intensamente a atribuição de rótulos para si, acaba "comprando" a ação de censurar, de produzir uma etiqueta - interna à profissão - a outros indivíduos que não seguem seu próprio conjunto de regras. 0 conceito de outsider - profundamente situacional - se aplica perfeitamente à situação, quando, em um primeiro momento, o guardador defende-se do rótulo, estabelecendo e cumprindo, nesse processo defensivo, um conjunto de regras, que vão, desde o horário rígido dos dias da semana, um ponto fixo e o conhecimento dos clientes, até a postura ativa e "bem-humorada" para tratá-los. 0 outsider se torna, rapidamente, um empreendedor moral quando - ao perceber outros de sua profissão que não seguem este conjunto de regras e que, consequentemente, "prejudicam a todos", trazendo uma imagem ruim para a sua rua, na qual já estabeleceu relações de confiança necessárias, conhece os comerciantes, os transeuntes - classifica-os como desviantes. Neste segundo momento, os guardadores-morais utilizam do rótulo para diferenciarem-se como trabalhadores sérios, que são conhecidos de "todo o pessoal”, diferentemente dos guardadores-imorais. 0 guardador-moral visa afirmar e construir uma identidade profissional, daquele que, apesar de mal visto, é um vencedor, que ascende e conquista "amigos" de forma honesta e, aos poucos, consegue diminuir os efeitos do desvio que está associado a sua trajetória social e profissional.

\section{Conclusão}

A profissão que tem a rua como seu cotidiano de trabalho está sujeita a influência da moralidade deste espaço, tanto na identificação dos indivíduos por outrem, através do estranhamento, como a reflexão dos próprios trabalhadores da rua, que percebem que sua condição é sujeita a etiquetações desviantes, e que sua posição moral está constantemente colocada à prova.

Este estudo foi realizado com base na percepção de si, de um determinado grupo de atores - os guardadores de carro - e buscou analisar como interpretam e descrevem sua própria pessoa, vista por outros atores, pertencentes a sua rotina de trabalho e de vida social. Teve como objetivo buscar compreender a profissão do guardador de carro a partir de sua própria perspectiva, sua ligação com os transeuntes do 
do espaço que ocupa na cidade e com seus clientes, suas experiências de trabalho e de vida e seu conflito com a dimensão do crime e da marginalidade, muito próxima de seu cotidiano.

É importante ressaltar as inúmeras possibilidades que esse estudo deixa em aberto. Entender as visões e percepções dos outros atores envolvidos, que estabelecem relações com este grupo profissional, daria acesso a uma perspectiva mais geral, que transcenderia este artigo. Tanto do ponto de vista institucional, da administração pública municipal através da palavra da Secretaria de Mobilidade Urbana - com a qual foi realizada uma entrevista considerada insuficiente para realizar conclusões -, como das visões dos clientes, dos donos de estabelecimentos comerciais que possibilitariam a construção de um cenário mais rico de interações e narrativas subjetivas. A trama de sociabilidade estabelecida de maneira criativa pelo guardador, com todos estes atores da sua rua/quadra é uma expansão relevante para futuros estudos.

0 processo de aprendizado se deu tanto nas entrevistas realizadas como nas negativas ou dificuldade de contato. Além dos entrevistados, entrei em contato com várias outras pessoas, guardadores ou não, que faziam parte da rotina dos trabalhadores entrevistados e que forneceram informações ou insights importantes. Minha própria caminhada pela cidade, como usuário e ao mesmo tempo cientista social, permitiu reflexões fundamentais. Com a experiência de pesquisa, pude conhecer e analisar uma profissão inserida nas contradições e incertezas do "viver na rua" e que apesar disso, busca construir uma identidade profissional baseada no reconhecimento de si. A pesquisa fornece ferramentas que auxiliam na reflexão sobre os desdobramentos das formas de trabalho na sociedade capitalista contemporânea.

\section{Referências Bibliográficas}

ARON, Raymond. As etapas do pensamento sociológico. São Paulo: Martins Fontes, 2008.

BECKER, Howard S.. Outsiders: estudos de sociologia do desvio. Rio de Janeiro: Zahar, 2008.

DAMATTA, Roberto. Carnavais, malandros e heróis: para uma sociologia do dilema brasileiro. Rio de Janeiro: Rocco, 1997.

DUBAR, Claude. A Socialização: Construção das identidades sociais e profissionais. Porto: Porto Editora, 1997. 
A crise das identidades: interpretação de uma mutação. São Paulo: EDUSP, 2009.

DUBET, François. Sociologia da Experiência. Lisboa: Instituto Piaget, 1994.

GASPAR, M. D. Garotas de Programa: prostituição em Copacabana e identidade social. Rio de Janeiro: Zahar, 1985.

HUGUES, Everett E.. (1958). Men and their Work. Free Press, Glencoe. 1958. Digitalizado por: University of Florida, George A. Smathers Libraries with support from LYRASIS and the Sloan Foundation.

LEFEBVRE, Henri. A Revolução Urbana. Belo Horizonte: UFMG, 1999.

NORONHA, Eduardo G.. "Informal”, Ilegal, Injusto: percepções do mercado de trabalho no Brasil. Revista Brasileira de Ciências Sociais. Vol.18 nº 53, 2003. Disponível em < http://www.scielo.br/scielo.php?script=sci_arttext\&pid=S0102-69092003000300007> Acesso em 09 mai. 2017.

OFFE, Claus. Trabalho e Sociedade: problemas estruturais e perspectivas para o futuro da sociedade do trabalho. Rio de Janeiro: Tempo Brasileiro, 1989.

SANTOS, Wanderley Guilherme dos. Cidadania e Justiça. Rio de Janeiro: Editora Campus, 1979.

SENNETT, Richard. A Cultura do Novo Capitalismo. Rio de Janeiro: Record, 2008.

THEODORO, M. As características do mercado de trabalho e as origens da informalidade no Brasil. In: Arrochellas, M. H. \& Ramalho, J. P. (orgs.). Desenvolvimento, subsistência e trabalho informal no Brasil. Petrópolis: Centro Alceu Amoroso Lima para a Liberdade, 2004.

VELHO, Gilberto. Um antropólogo na Cidade: ensaios de antropologia urbana. Obra organizada por: Vianna, H.; Koschnir, K; Castro, C. (orgs.). Rio de Janeiro: Zahar, 2013.

Recebido em março/2015.

Aprovado em outubro/2015. 